\title{
The Impact of the COVID-19 Lockdown on Obstetrics Practice at a Rural Based Tertiary Care Centre: An Analytical Crossectional Study
}

\author{
Dr. Amrita Singh ${ }^{* 1}$, Dr. Anjali Kawthalkar ${ }^{2}$, Jaydeep Nyase ${ }^{3}$, Dr. Priya Sontakke ${ }^{4}$ \\ ${ }^{1}$ Assistant professor, Dept. of Obstetrics and Gynaecology, NKPSIMS Medical College Nagpur, Maharashtra, India; \\ singh.amrita686@gmail.com \\ ${ }^{2}$ Professor and unit in charge, Dept. of Obstetrics and Gynaecology, NKPSIMS Medical College, Nagpur; \\ anjalikawthalkar@gmail.com \\ ${ }^{3}$ Lecturer cum statistician, NKPSIMS Medical College, Nagpur; jaydeepnayse@gmail.com \\ ${ }^{4}$ Junior Resident 3 Dept. of Obstetrics and Gynaecology, NKPSIMS Medical College, Nagpur; \\ priyasontakke.ps@gmail.com
}

*Corresponding Author: Dr. Amrita Singh; singh.amrita686@gmail.com

Received 13 September 2021;

Accepted 28 October 2021;

Published 10 November 2021

\begin{abstract}
Objective: To evaluate the impact of the COVID-19 lockdown on obstetrics practise in a tertiary care centre. Methods: Analytical Crossectional observational study was conducted in the obsgyn department from Jan 2020 to June 2020.There were two groups pre lockdown (Group B) and post lockdown (Group A) of 180 women in each group. Results were analysed using Epi info software version 7. Results: There was significant $(\mathrm{p}<0.001)$ rise in LSCS rates $(80 \%)$ in post lockdown period as compared to prelockdown $(50 \%)$. Emergency LSCS (87.5\%) was seen more during pandemics as compared to elective LSCS (12.5\%). Elective LSCS was seen more prior to lockdown. The gestational age during admission in lockdown was more in $<37$ weeks gestation group with complications or $>40$ weeks. Significant rise (p<0.001) in IUD (13.3\%), NICU admissions (23.3\%) were noted during lockdown as compared to prelockdown (6.6\%), (10\%). Hospital stay was reduced from 4 days to 3 days during the lockdown. Conclusion: Lockdown affects obstetrics outcome adversely. There is an urgent need to sensitize antenatal women as well as health care workers to continue the routine obstetrics care, especially in the second half of pregnancy with covid appropriate behaviour.
\end{abstract}

Keywords: COVID - 19, Lockdown, LSCS, IUD, NICU.

\section{Introduction}

The first documented case of COVID 19 was found in Wuhan (China) on December 31, $2019^{[1]}$. It has since rapidly spread across the globe, to be declared a pandemic by the World Health Organization (WHO) on March 11, $2020{ }^{[2]}$. The lockdown in Wuhan played a critical role in limiting the scope of the COVID19 epidemic in China.

India too launched this only effective, available option of strict lockdown to contain the threat of pandemic, on 25th march 2020.

However, few have hypothesized that such nonpharmaceutical interventions might be less effective in settings with large informal economies and limited ability to respond to increases in cases of severe disease ${ }^{[3]}$, and that their risks might outweigh their benefits ${ }^{[4]}$.

The mass restriction of activities was mainly intended to prevent community spread of the infection and to allow for preparedness of the medical services for the pandemic. But as seen in previous epidemics in the past, health systems were crippled to provide routine services to a large extent due to the sudden increase in demand and the redirection of the workforce towards the epidemics.

Hence, the routine healthcare system was disrupted and people faced problems when seeking medical advice ${ }^{[5]}$.

Hospital activities had been partially reorganized, suspending all outpatient activities (including non-urgent and deferred visits) and permitting only emergencies. 
The concept of telemedicine was introduced to bridge this gap, but certain diagnosis can be picked when examined patients physically and pregnancy is one of them.

In spite of so many welfare policies in place, maternal health system is still weak in many low resource setting nations and pandemic like this brings a jolt to the care of pregnant women as well and widens the gap further by its direct and indirect impact.

In the past months, scholars began to pay attention to the management of pregnancy and childbirth during the COVID-19 pandemic. The Ministry of Health and Family Welfare, India (MOHFW) and FOGSI (Federation of Obstetricians \& Gynaecologists of India) declared pregnant women to be a highrisk group and mandated guidelines to provide essential maternal health services as well as to patients with suspected or confirmed COVID-19 ${ }^{[6]}$. Guidelines have been laid down for modified prenatal care ${ }^{[7-10]}$.

Although the possible risks associated with COVID-19 and the clinical characteristics of pregnant women with laboratoryconfirmed COVID-19 have been investigated [11,12], previous research has failed to address the impact of lockdown during the COVID-19 pandemic on antenatal care.

The aim of this study was to evaluate the impact of the COVID-19 lockdown on obstetrics practise in a tertiary care centre.

In this study we analysed the data between pre lockdown and post lockdown period in terms of LSCS rates, Maternal and perinatal outcomes and complications.

\section{Methods}

Study Setting: Department of obstetrics and Gynaecology at NKPSIMS Nagpur.

Data Collection: Data was collected from patients file from medical record department of the college. Further data was recorded in the emergency room from the time of admission to discharge.

Study Design and patients: An analytical crossectional observational study was done in the NKPSIMS Nagpur from Jan
2020 to June 2020, Pre lockdown data compared with post lockdown data. The study included only the obstetrics patients who presented to emergency department and excluded gynecological emergencies. The following were evaluated: Gestational age of the patient when admitted, mode of delivery, perinatal outcome, maternal comorbidities, complications encountered and the total duration of stay.

\section{Ethical Approval}

The protocol was reviewed and approved by Institutional Ethics Committee

\section{Statistical method}

Statistical analysis was done by using Epi info software version 7 . For quantitative data: Frequency and percentage was used.

For quantitative data: Mean and Standard deviation, Standard error of mean was used.

\section{Inferential Statistics}

For Qualitative data: Chi Square test was used.

For Quantitate data: unpaired ' $t$ ' test was used.

Level of Significance $=0.05$.

\section{Sample size calculation}

It was done by Pilot Study. Total 30 in group A and 30 in group B was taken. Required Sample size as per pilot study was 180 in each group A and B.

\section{Results}

Total pregnant patients were divided into two groups A and B.

Group A included pregnant women post lockdown.

Group B included pre lockdown pregnant women patients.

Both the group included 180/180 patients.

Most patients in group A arrived mostly either at $<37$ weeks with some complications or 39-40 weeks, often late, as depicted in table 1

Table 1: Gestational Age

\begin{tabular}{|l|l|l|l|}
\hline Gestational Age(wks) & $\begin{array}{l}\text { Group A (post lockdown) } \\
\mathbf{n}\end{array}$ & $\begin{array}{l}\text { Group B (prelockdown) } \\
\mathbf{n}\end{array}$ & Total \\
\hline$<37$ & $90(50.0 \%)$ & $60(33.3 \%)$ & 150 \\
\hline $37-38$ & $12(6.7 \%)$ & $30(16.7 \%)$ & 42 \\
\hline $38-39$ & $30(16.6 \%)$ & $60(33.3 \%)$ & 90 \\
\hline $39-40$ & $36(20 \%)$ & $18(10 \%)$ & 54 \\
\hline$>40$ & $12(6.66 \%)$ & $12(6.66 \%)$ & 24 \\
\hline Total & 180 & 180 & 360 \\
\hline
\end{tabular}

The chi-square statistic is 29.7143. The p-value is $<0.00001$. The result is significant at $p<.05$.

LSCS was found more in group A (post lockdown). Table 2

Table 2: Mode of delivery

\begin{tabular}{|l|l|l|l|}
\hline MODE OF DELIVERY & LSCS(n) & VD (vaginal delivery) (n) & Total \\
\hline Group A & $144(80 \%)$ & $36(20 \%)$ & 180 \\
\hline Group B & $90(50 \%)$ & $90(50 \%)$ & 180 \\
\hline
\end{tabular}

The chi-square statistic is 35.6044. The p-value is $<0.00001$. Significant at $p<.05$

And most of the LSCS post lockdown were emergency LSCS. 
Table 3: Type of LSCS

\begin{tabular}{|l|l|l|l|}
\hline & Emergency(n) & Elective(n) & Total \\
\hline Group A & $126(87.5 \%)$ & $18(12.5 \%)$ & 144 \\
\hline Group B & $54(60 \%)$ & $36(40 \%)$ & 90 \\
\hline
\end{tabular}

The chi-square statistic is 23.595. The p-value is $<0.00001$. Significant at $p<.05$.

Among the maternal comorbidities, Antepartum haemorrhage, was found more in Group A.

Table 4: Maternal comorbidity

\begin{tabular}{|l|l|l|}
\hline & Group A(n) & Group B(n) \\
\hline Antepartum hemorrhage & $42(23.33 \%)$ & $12(6.66 \%)$ \\
\hline Gestational Diabetes & $6(3.33 \%)$ & 0 \\
\hline Hypertensive Diseases of pregnancy & $18(10 \%)$ & $6(3.33 \%)$ \\
\hline Oligohydramnios & $6(3.33 \%)$ & $24(13.33 \%)$ \\
\hline Polyhydramnios & 0 & $6(3.33 \%)$ \\
\hline Postpartum pyrexia & $6(3.33 \%)$ & 0 \\
\hline
\end{tabular}

Most of the Intrauterine deaths, NICU admissions happened in post lockdown Group A. In group B most babies were mother side.

Table 5: Perinatal and neonatal outcome

\begin{tabular}{|l|l|l|}
\hline & Group A (n) & Group B (n) \\
\hline Mother side & $108(60 \%)$ & $144(80 \%)$ \\
\hline Intrauterine deaths (IUD) & $24(13.3 \%)$ & $12(6.66 \%)$ \\
\hline Neonatal deaths (NND) & $6(3.33 \%)$ & $6(3.33 \%)$ \\
\hline NICU & $42(23.33 \%)$ & $18(10 \%)$ \\
\hline
\end{tabular}

The chi-square statistic is 18.7429. The p-value is .000309. The result is significant at $p<.05$.

Mean Duration of hospital stay was less in post lockdown period, Group A.

Table 6: Duration of Hospital stay

\begin{tabular}{|l|l|l|l|l|l|l|l|}
\hline Group Statistics & Group & N & Mean (In Days) & Std. Deviation & Std. Error Mean & t value & p value \\
\hline \multirow{2}{*}{ Hospital stays } & A & 180 & 3.30 & 1.149 & 0.210 & -5.05 & $<0.001$ \\
\cline { 2 - 7 } & B & 180 & 4.00 & 1.462 & 0.267 & \\
\hline
\end{tabular}

\section{Discussion}

To address the critical situation of corona, the lockdown was imposed, but there are reasons to be concerned.

Study like this and its findings can reveal the impact of these never seen prolong lockdown effect on obstetrics practise.

In our study we found that most patients in post lockdown months had LSCS compared to prelockdown period. From the gathered data it was observed most patients came late for admissions due to various reasons, one of them certainly being non available of timely transport, mostly at 40-41weeks and often came with foetal distress.

Other reason from indications of LSCS could be seen, as many women out of COVID fear opted themselves for LSCS to avoid prolonged labour and thus prolonged stay.

Many came with severe preeclampsia and late presentation and thus higher rates of LSCS. Many obstetric emergencies like Abruptio, eclampsia, missed placenta previa were encountered in post lockdown period. It could be assumed this could be due to restricted antenatal visits and thus negligence of high-risk pregnancies.

Elective procedures were brought to still and hence rates of elective LSCS fell and the upsurge of emergency LSCS.

One of the indications for elective LSCS is abnormal lie, when the normal vaginal delivery is not possible, turned up during emergency hours, in active labour, and thus ended up with emergency LSCS. It could be due to closure of OPD's and hence these women could not be picked up in routine hours.
During strict lockdown, transportation services were at halt, small nursing homes were closed, pregnant women considered as vulnerable group, were forced to sit back at home and came out only with emergency complaints. Due to delay in reaching tertiary care centres as emergency ambulances were also busy catering COVID patients, maternal comorbidities and casualties occurred more.

This affected the neonatal outcome as well. More NICU admissions, Intrauterine deaths and neonatal deaths, which was unlikely to be directly caused by viral infection since none of the women had COVID-19. Possible explanations for this observation include indirect effects, such as reluctance of pregnant women to attend hospital because of fear of contracting severe acute respiratory syndrome coronavirus 2, or changes in obstetric services ${ }^{[13]}$. During the COVID-19 outbreak, a study from Nepal revealed a reduction in the number of hospital births, as well as a rise in stillbirths and neonatal mortality during lockdown ${ }^{[14]}$.

Even the hospital stay was curtailed during post lockdown period, to avoid unnecessary prolong stay and increase chances of getting COVID.

LSCS patients were discharged after 3 days and normal delivery after 1day hrs. Earlier pre lockdown era LSCS patients were discharged after 5 days and normal delivery after 2 days in our institute. No patients, post discharge came with any significant complaints. Out of this study we can also conclude that maybe we can cut short the hospital stays to minimum to minimise further hospital acquired infections, especially during pandemics.

It was also seen that, there were very few non emergent conditions requiring admissions in post lockdown period. This 
could be due to the fear with which people didn't turn to hospitals and manged at home, or getting rest at home due to lockdown and hence not getting physically stressed and hence fewer minor ailments. This could be another area of research in future.

The strength of our study being first of its kind and observational, where patients were followed till the end. It was done when the lockdown was first imposed and whole world was busy managing the pandemic, unintentionally loosing focus on other health department. Limitation being, single centre study. We need more multi centric studies to generalise the results to the whole population.

\section{Conclusion}

Post lockdown we saw more maternal and perinatal morbidities. The COVID per se didn't affect the pregnancies much but the lockdown had significant effect on obstetrics and neonatal care. We believe there should we urgent evaluation of obstetrics services by the concerned bodies to plan for future pandemic jolts. The routine antenatal care should continue as usual, specially in the second half of the pregnancy when the delivery time is near, so that maternal and neonatal outcomes could be stabilised. In the first half though there can be relaxation in the number of antenatal visits. People should also be educated about how to follow covid protocol norms and utilise health services as well. Stay home stay safe is indeed needed but not at the cost of health.

\section{Conflict of interest}

None

\section{Author contribution}

Dr Amrita Singh: Principal investigator

Dr Anjali Kawthalkar: helped in writeup

Jaydeed Nayse: statistical analysis

Dr Priya Sontakke: Data collection

\section{References}

[1] Lu H, Stratton CW, Tang Y. Outbreak of pneumonia of unknown etiology in Whuan China: The mistery and the miracle. J Med Virol.2020;92:401-402.

[2] Cucinotta D, Vanelli M. WHO declares COVID-19 a pandemic. Acta Biomed. 2020;91(1):157-160.

[3] Dahab M, van Zandvoort K, Flasche S, et al. COVID-19 control in low-income settings and displaced populations: what can realistically be done? Pre-print. Available

at: https://www.lshtm.ac.uk/newsevents/news/2020/covid19-control-low-income-settings-and-displacedpopulations-what-can\#.XnpKCXF93Fc.email. Accessed: 1 May 20202020

[4] Greenstone M, Nigam V. Does Social Distancing Matter? SSRN Electronic Journal 2020. doi: 10.2139/ssrn.3561244 [CrossRef] [Google Schola

[5] Wilhelm JA, Helleringer S. Utilization of non-Ebola health care services during Ebola outbreaks: a systematic review and meta-analysis.J Global Health. 2019;9(1):10406

[6] Chawla D, Chirla D, Dalwai S, et al. Perinatal-Neonatal Management of COVID-19 Infection - Guidelines of the Federation of Obstetric and Gynaecological Societies of India (FOGSI), National Neonatology Forum of India (NNF), and Indian Academy of Pediatrics (IAP). Indian Pediatr. 2020;57(6):536-548.

[7] Novel Coronavirus 2019 (COVID-19), ACOG practice advisory July 2020.

https://www.acog.org/clinical/clinical guidance/practiceadvisory/articles/2020/03/novelcoronavirus-2019. Accessed October 8, 2020

[8] Guidance for Management of Pregnant Women in COVID-19 Pandemic ICMR.https://www.icmr.gov.in/pdf/covid/techdoc/Guida nce for Management of Pregnant Women in COVID 19 Pandemic 12042 020.pdf

[9] COVID-19 Resourceshttps://www.figo.org/resources/COVID -19-resources. Accessed October 4, 2020

[10] Coronavirus infection and pregnancy - RCOG. https://www.rcog.org.uk/en/guide lines -researchservices/guide lines/ coronavirus-pregnancy/COVID -19virus -infection-and-pregnancy/. Accessed September 30, 2020

[11] CovidSurg Collaborative, Nepogodiev D, Bhangu A. Elective surgery cancellations due to the COVID-19 pandemic: global predictive modelling to inform surgical recovery plans. Br J Surg. 2020; https://doi.org/10.1002/bjs.11746. Online ahead of print.

[12] Qiao J. What are the risks of COVID-19 infection in pregnant women? The Lancet. 2020, 395(10226):760762.

[13] Royal College of Obstetricians and Gynaecologists Coronavirus (COVID-19) infection in pregnancy. Version

11.https://www.rcog.org.uk/globalassets/documents/guid elines/2020-07-24-coronavirus-covid-19-infection-inpregnancy.pdf Date: July 24, 2020

[14] Ashish KC, Gurung R, Kinney MV, et al. Effect of the COVID-19 pandemic response on intrapartum care, stillbirth, and neonatal mortality outcomes in Nepal: a prospective observational study. Lancet Glob Health. 2020;8(10):e1273-e1281

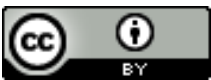

Open Access This article is licensed under a Creative Commons Attribution 4.0 International License, which permits use, sharing, adaptation, distribution and reproduction in any medium or format, as long as you give appropriate credit to the original author(s) and the source, provide a link to the Creative Commons license, and indicate if changes were made. The images or other third party material in this article are included in the article's Creative Commons license, unless indicated otherwise in a credit line to the material. If material is not included in the article's Creative Commons license and your intended use is not permitted by statutory regulation or exceeds the permitted use, you will need to obtain permission directly from the copyright holder. To view a copy of this license, visit https://creativecommons.org/licenses/by/4.0/.

(C) The Author(s) 2021 